\title{
ISLAM DAN BUDAYA BANJAR DI KALIMANTAN SELATAN
}

\author{
Oleh: Hasan*
}

\begin{abstract}
Abstrak
Dewasa ini kearifan lokal semakin digiatkan kembali oleh pemerintah sebagai identitas sebuah budaya lokal. Karena setiap budaya akan menghasilkan produk budaya baik itu tradisi maupun kesenian yang mencerminkan identitas dari budaya tersebut. Dalam budaya Banjar pun banyak tradisi lokal yang bersentuhan dengan Islam. Ketika agama datang ke satu masyarakat, tentu masyarakat tersebut telah memiliki kebudayaan yang dijadikan petunjuk dalam bertindak walaupun bersifat lokal, tidak universal. Ada atau tidak ada agama, pedoman tersebut akan digunakan oleh masyarakat selama masih dianggap baik. Oleh karena itu, agama yang mempunyai kesesuaian dengan budaya setempat akan mudah diterima dan cepat berkembang. Sebaliknya, agama yang berlawanan secara diametral (garis pemisah) dengan kebudayaan akan ditolak oleh masyarakat.
\end{abstract}

Kata Kunci: Islam, budaya, tradisi

\section{A. Pendahuluan}

Mendiskusikan Islam dan budaya lokal seolah-olah mencerminkan dua sisi yang bersifat binary opposition, saling bertolak belakang. Kesan ini muncul dan diperkuat oleh adanya image dari sebagian masyarakat bahwa Islam adalah agama samawi (langit) yang diturunkan di tanah Arab, yang memiliki netralitas dan terhindar dari pengaruh konteks sosio-budaya manapun. Pada sisi lain, Islam dipahami sebagai agama universal yang memiliki fleksibilitas, selaras dengan dinamika dan perkembangan sosial, budaya dan ekonomi masyarakat, sehingga muncul adagium Islam shohihun likulli makanai wa zamanin. Islam sebagai sebuah agama universal (rahmatan lil 'alamin), yang adaptable, acceptable serta capable untuk tumbuh dan berkembang secara dinamis di segala tempat dan waktu bersifat konfirmatif dan adaptatif.

Konfirmatif dalam arti Islam selalu selektif dalam mengadopsi nilai budaya dan tradisi yang berkembang di tengah-tengah kehidupan masyarakat lokal. Jika sekiranya nilai budaya dan tradisi lokal itu bertentangan dengan nafas Islam, maka dalam konteks inilah Islam melakukan reformasi budaya

*Penulis adalah dosen tetap pada STIQ (Sekolah Tinggi Ilmu Al Qur'an) Amuntai. 
(cultural reform) sehingga nilai-nilai yang terkandung di dalam budaya lokal tetap selaras dengan nilai-nilai Islam (Islamisasi budaya).

Hal tersebut diperlukan lantaran pengaruh lokalitas dan tradisi dalam kelompok suatu masyarakat bangsa sulit dihindari. Namun demikian, partikularitas dan universalitas Islam tentu tidak akan luntur hanya karena dinamika tradisi dan budaya masyarakat lokal. Islam yang universal tetap menjadi pedoman dalam segala aspek kehidupan. Hanya saja pergumulan Islam dan budaya lokal itu berakibat pada adanya keragaman penerapan prinsip-prinsip umum dan universal suatu agama berkenaan dengan tata caranya (technicalities).

Islam yang dalam sejarahnya lahir di tanah Arab, tetapi dalam dinamikanya, seperti kita semua saksikan, tidak harus terikat oleh budaya Arab, melainkan senantiasa beradaptasi (menyesuaikan diri) dengan segala lingkungan sosial di mana Islam dipraktikkan dan dikembangkan. Dalam kaitannya dengan budaya lokal, Islam memiliki kekuatan koersif dalam mengintegrasikan budaya lokal sesuai dengan sistem nilai dan sistem simbol dalam Islam dengan berpijak pada prinsip theocentric-humanis.

\section{B. Pembahasan}

\section{Suku bangsa Banjar}

Di Kalimantan Selatan, yang biasa disebut sebagai orang Banjar adalah penduduk (asli) daerah sekitar kota Banjarmasin (wilayah Sungai Jingah, Kuin dan Kampung Melayu). Daerah ini meluas sampai Kota Martapura, ibukota Kabupaten Banjar dan wilayah sekitarnya.

Bahasa yang digunakan oleh masyarakat Banjar adalah bahasa Banjar. Bahasa Banjar sejatinya adalah pecahan dari bahasa Melayu. Karena diduga kuat bahwasanya nenek moyang masyarakat Banjar adalah berintikan pecahan suku bangsa Melayu yang dikembangkan oleh suku bangsa yang mendiami Sumatera dan Tanah Semenanjung Melayu (sekarang Malaysia Barat) sekitar lebih dari seribu tahun yang lalu berimigrasi secara besar-besaran ke kawasan Kalimantan khususnya Kalimantan Selatan (Alfani Daud, 1997; 65). Mereka memasuki daerah-daerah Kalimantan dari arah Selatan, Laut Jawa, pada waktu daerah rawa-rawa yang luas, yang membentuk provinsi Kalimantan Selatan dan Kalimantan Tengah saat ini, masih merupakan teluk raksasa dengan pantai sebelah timurnya berada di kaki pegunungan Meratus. Cikal bakal nenek moyang orang-orang Banjar itu mendiami sungai-sungai yang bermuara di teluk raksasa dan membangun pemukiman di tepi-tepi sungai yang semuanya berhulu di kaki pegunungan Meratus.

Ketika mereka tiba di kawasan ini, mereka berjumpa dengan suku bangsa yang lebih dulu dikenal dengan nama orang Dayak yaitu suku Dayak pegunungan Meratus (suku Dayak Bukit), suku Dayak Manyan, suku Dayak Ngaju dan suku Dayak Lawangan. Meskipun suku Dayak Bukit lebih mungkin 
sama asal usulnya dengan cikal bakal nenek moyang Banjar, namun mereka tetap merupakan kelompok terpisah dengan masyarakat Banjar. Karena semakin banyaknya pindahan dari Sumatera maka terdesaklah orang Dayak tersebut dan mereka berpindah ke daerah pegunungan Meratus.

\section{Sejarah Masuknya Islam di Kalimantan Selatan}

Kalimantan Selatan adalah salah satu pulau terbesar di dunia yang memiliki hutan-hutan yang lebat dan menghasilkan hasil alam yang melimpah seperti damar, rotan, kayu dan lain-lain. Oleh karena alasan tersebut, banyak sekali pedagang dari luar Kalimantan berlayar ke sana untuk mendapatkannya. Pedagang-pedagang tersebut selain berdagang mereka juga berusaha menyebarkan agama yang dianutnya.

Sebelum Islam masuk ke pulau Kalimantan, penduduknya telah memeluk agama Hindu-Budha atau memeluk kepercayaan Kaharingan yang tentu saja sangat berbeda dengan ajaran Islam. Walaupun proses Islamisasi masyarakat Kalimantan hingga kini terus berjalan melalui dakwah dan pendidikan, akan tetapi bekas-bekas kepercayaan dan budaya agama sebelumnya, tidak sepenuhnya bisa dikikis sehingga sebagian masih berpengaruh terhadap keberagamaan dan kebudayaan umat Islam hingga sekarang ini (Kamrani Buseri, 2009; 65).

Para ahli sejarah (historian) belum dapat dengan pasti mengatakan tahun kedatangan Islam di Kalimantan Selatan, dengan alasan kesulitan menemukan data untuk mengungkap hal itu (Mukhyar Sani, 2003; 31). Akan tetapi mereka kebanyakan mengatakan bahwa tahun $1540 \mathrm{M}$ merupakan tahun di mana Islam diterima secara resmi oleh raja kerajaan Banjar Pangeran Samudera yang kemudian berganti nama dengan Pangeran Suriansyah. Dalam makalah Hamka yang berjudul "Meninjau Masuknya Islam ke Kalimantan Selatan" dan disampaikan dalam seminar Masuknya Islam tahun 1973, Hamka menyimpulkan bahwa:

1. Tersebarnya agama Islam ke Kalimantan Selatan sebenarnya terjadi lama sebelum berdirinya kerajaan Islam Banjar di Banjarmasin, yitu diperkirakan pada akhir abad ke $14 \mathrm{M}$.

2. Penyebar Islam adalah para pedagang sekaligus ulama sebagai hasil dari hubungan timbal-balik antara Singapura-Malaka, kemudian Pasai dan Aceh dengan tanah Banjar serta Marabahan (pelabuhan) yang ramai pada masa pemerintahan Raden Sari Kaburangan dan Pangeran Temenggung.

3. Berdirinya kerajaan Islam di Demak (Jawa Tengah) pada sekitar tahun 1500 $\mathrm{M}$, dan adanya hubungan orang Islam dengan pantai antara Jawa Timur dan Surabaya, semakin mempercepat proses berdirinya kerajaan Islam Banjar (Saifuddin Zuhri, 1980; 399-402).

4. Ikatan kebudayaan bahasa Melayu yang dipakai sebagai bahasa pengantar dengan tulisan Arab-Melayu (Pegon) dalam buku-buku pelajaran agama Islam yang pertama dikarang yaitu Sabil al-Muhtadin dan Kitab Parukunan 
di Kalimantan Selatan yang menunjukkan adanya hubungan erat dengan Semenanjung Malaka.

Sejarah zaman kerajaan Hindu/Budha di Negara Dipa Amuntai, pelabuhan-pelabuhan di Kalimantan Selatan sudah mulai ramai dikunjungi para pedagang Jawa, Sumatera, Semenanjung Malaka, Sulawesi bahkan yang jauh yaitu dari Arab. Kuat dugaan antara pedagang-pedagang itu sebagian beragama Islam, sambil berdagang mereka melakukan misi dakwah Islamiyah di tempat-tempat yang mereka singgahi. Di antara mereka ada pula yang menetap dan melakukan asimilasi, menikah dengan wanita setempat setelah meng-Islam-kannya terlebih dahulu. Di tempat itu kemudian mereka melakukan dakwah Islam secara cultural. Pendapat yang demikian ini pun dinyatakan sejarawan Abdul Muis. Bahwa masuk dan tersebarnya Islam di Kalimantan Selatan adalah dengan cara damai setelah berpuluh-puluh tahun kemudian pemeluk agama Islam berangsur-angsur membentuk masyarakat Islam dan pada akhirnya berdirinya kerajaan Islam Banjar (Saifuddin Zuhri, 1980 ; 304), di mana pada permulaannya dibawa oleh para pedagang dan da'ida'i Islam secara personal dan melalui perkawinan dengan wanita setempat, sebagaimana juga tersiarnya Islam di daerah Indonesia lainnya, seperti di Jawa.

Sebelum Islam datang, di kepulauan Nusantara berkembang agama Hindu, waktu itu kerajaan Hindu diperintah oleh Prabu Brawijaya, putera Angka Wijaya (Riwut, 1979; 181). Hubungan Kalimantan dengan Jawa sudah ada sejak zaman Hindu Majapahit hingga berlangsung pada zaman Islam Demak. Hubungan tersebut melalui laut Jawa. Oleh karena itu lalu lintas perdagangan antara Gresik dan Tuban dengan pelabuhan Banjar sudah lama terbentuk. Mayoritas penduduk Banjar berada di pinggir sungai maka mempermudah pedagang berdagang sekaligus berdakwah di sana.

Pada tahun 1595, pasukan kerajaan Demak datang memasuki wilayah Banjar dan kemudian antara kedua kerajaan itu mengadakan kompromi saling membantu satu sama lain dan menghasilkan dua point yang penting, yakni saling tukar barang-barang dagangan, bahan pakaian serta rempah-rempah dan Pangeran Samudera harus masuk Islam serta menerima penghulu agama Khatib Dayyan sebagai seorang yang menyebarkan agama Islam di dalam kerajaan Banjar.

Setelah diterima di kerajaan Banjar Khatib Dayyan melaksanakan tugasnya untuk menyebarkan agama Islam, sebelumnya dakwah Islam Cuma di daerah pinggiran setelah adanya Khatib Dayyan dakwah Islam sampai ke pedalaman Kalimantan Selatan. Akan tetapi upaya dakwah ini masih belum diimbangi dengan pembinaan dan peningkatan ilmu pengetahuan keislaman sehingga masyarakat yang telah masuk Islam dengan tidak sadar masih terpengaruh agama Hindu dan Budha.

Perkembangan agama Islam dan peningkatan ilmu keislaman tampaknya dimulai pada abad ke 18 yaitu di zaman ulama besar Muhammad Arsyad (1710-1812 M). (Fathullah Munadi, 2011; 42-43). 
Saat itu dakwah Islam menggunakan metode pengajian dan pendidikan Islam di langgar (surau). Untuk mempermudah dakwah Islam Muhammad Arsyad mengarang kitab baik fiqh, tauhid, tasawuf dan lain-lain.

\section{Islam dan Budaya Banjar}

Banyak sekali budaya lokal yang masih sampai sekarang dilakukan di daerah Banjarmasin dan sekitarnya. Baik budaya tersebut dilakukan secara periodik dan bersifat sesuai dengan kebutuhan masyarakat. Di antaranya adalah hari al-Syura dan bubur al-Syura, maulidan, baayun maulid, batampung tawar, bapalas bidan

\section{a. Hari al-Syura (10 Muharram) dan Bubur al-Syura}

Muharram adalah bulan pertama dalam tahun Islam (Hijrah). Sebelum Rasulullah berhijrah dari Mekkah ke Yatsrib, penamaan bulan dibuat mengikuti tahun Masehi. Hijrah Rasulullah memberi kesan besar kepada Islam sama ada dari sudut dakwah Rasulullah, ukhuwah dan syiar Islam itu sendiri. Karena banyaknya peristiwa-peristiwa yang menakjubkan di hari tersebut, maka agama menyuruh (sunnat) untuk melaksanakan puasa di hari tersebut. Selain disunnahkan puasa, kita juga disunnahkan untuk berbagi dengan anak yatim dan orang yang membutuhkan lainnya.

Dalam masyarakat Banjar, masih banyak ditemukan pembuatan bubur al- Syura yang dibuat bertepatan dengan tanggal 10 Muharram tiap tahunnya. Kenapa dinamakan dengan bubur al-Syura, karena di hari itulah masyarakat Banjar bergotong-royong membuatnya. Keistimewaan bubur al-Syura masyarakat Banjar adalah bahan-bahan yang digunakan dalam pembuatannya. Konon katanya, bahan-bahan yang digunakan berjumlah lebih dari 40 buah macam bahan. Biasanya bubur al-Syura terbuat dari beras yang dimasak dengan Santan dan dicampur dengan segala sayur-sayuran. Menurut Daud, pembuatan bubur ini merupakan kenangan terhadap suatu peristiwa pada zaman dulu yang ketika itu selalu dalam kekurangan makanan, dikumpulkanlah segala macam tumbuh-tumbuhan yang ada di sekitar dan dicampur dengan segala persediaan bahan makanan yang ada menjadi bubur (Alfani Daud, 1997; 330-331). Tidaklah heran bahan bubur tersebut hampir 40 buah bahan.

Biasanya masyarakat Banjar mulai memasak bubur tersebut ketika siang hari dan mulai dibagi-bagikan ke masyarakat ketika sore hari (sekitar jam 4-5 sore) untuk dijadikan makanan berbuka puasa. Hikmah yang dapat diambil dalam pembuatan bubur ini adalah dapat dijadikan syiar Islam dan juga dapat mempererat tali silaturrahim antar masyarakat Banjar pada khususnya. 


\section{b. Maulidan}

Maulidan Berasal dari bahasa Arab maulid yang telah dibanjarkan untuk menunjukkan pada sebuah acara perayaan yang dikenal sebagai maulid Nabi yang berarti pada hari kelahiran Nabi Muhammad yang jatuh pada tanggal 12 Rabi'ul Awwal. Umat Islam banyak yang merayakannya dengan cara yang berbeda-beda, sesuai dengan pola kebudayaan masing-masing. Seperti yang ada di daerah Jawa misalnya di Keraton Yogyakarta, diadakan acara Grebek dengan dilengkapi acara ritual-ritual Jawa seperti mengarak benda-benda bersejarah punya sultan, mengarak makanan sampai ke masjid agung dan selanjutnya makanan tersebut diperebutkan masyarakat. Bulan Rabi'ul Awwal yang merupakan bulan kelahiran nabi Muhammad tersebut oleh orang Banjar disebut bulan maulid dan ada juga yang menyebutnya mulud. Kegiatan ini, meskipun tidak masuk dalam doktrin agama, sifatnya kultural tetapi merupakan fenomena universal di kalangan umat Islam di Kalimantan Selatan, Bahkan jika terdapat orang yang dalam ekonomi berkecupan tidak melaksanakan maulidan di rumahnya, maka dianggap tidak baik oleh orang sekitarnya.

Di daerah Kalimantan Selatan khususnya daerah Hulu Sungai (dari Kabupaten Tapin sampai Kabupaten Tabalong) ada kegiatan yang sangat mengagumkan, yaitu melaksanakan perayaan tahunan ini satu bulan penuh yang dibagi per-kampung, supaya tidak terjadi dalam satu hari bersamaan perayaan maulid dalam satu kampung. Keunikan tersendiri ialah perayaan maulid dalam satu kampung dipusatkan di masjid agung. Salah satu masjid yang digunakan sebagai tempat maulid akbar adalah masjid Keramat alMukarramah yang berada di Desa Banua Halat, Kecamatan Tapin Utara, Kabupaten Tapin.

Sebelum dilaksanakan maulid di masjid tersebut, orang kaya yang ada dalam kampung tersebut mengadakan perayaan maulid sendiri-sendiri dengan mengundang orang kampung sebelah mereka dan kerabat serta keluarga mereka di rumah. Dalam rumah itu dibacakan ayat-ayat suci Al-Quran dan setelah itu dilanjutkan dengan pembacaan Maulid Habsyi atau sering disebut dengan rawi (pembacaan biografi dengan bahasa Arab) yang diselingi dengan qasidah-qasidah yang menggunakan terbang sejenis marawis. Setelah selesai semua itu, ahlu al-bait menyuguhkan makanan bagi yang hadir dalam rumah tersebut. Setelah mereka selesai makan bersama-sama, mereka langsung menuju ke masjid agung untuk mengikuti maulid akbar yang juga dibacakan ayat-ayat Al Quran, Maulid Habsyi serta diadakan ceramah agama oleh kyai setempat atau dengan mendatangkan penceramah dari luar kota.

Dana yang digunakan untuk acara maulid ini biasanya berasal dari swadana masyarakat setempat yang dikumpulkan jauh-jauh hari sebelum acara tersebut dilaksanakan. Biasanya dibentuk kepengurusan untuk pencarian dana yang akan digunakan dalam acara tersebut. Selain dalam pencarian dana, mereka juga saling membantu dan berbagi tugas, ada yang membersihkan 
masjid, ada yang menjadi tukang masak, tukang parker dan lain sebagainya demi kelancaran acara maulid. Masjid agung dijadikan sebagai tempat maulid karena masjid mempunyai makna sebagai pemersatu masyarakat, serta alasan undangan yang berasal dari luar kota dengan mudah menujunya.

Sebagaimana biasanya, dalam maulid yang di masjid agung itu diadakan acara tahlilan dan ceramah agama yang berkaitan dengan maulid Nabi dengan tema keselamatan dunia dan akhirat. Dijelaskan penceramah bahwa keselamatan dunia dan akhirat dapat dicapai dengan apabila kita mencintai Nabi dengan mengikuti perintah dan menjauhi larangan dari Allah dan Nabi.

\section{c. Baayun Maulid}

Baayun (mengayun anak) maulid dilaksanakan ketika pembacaan maulid nabi saat bacaan yang harus dibaca dalam keadaan berdiri. Saat itulah anak diayun-ayun untuk mengharapkan berkah dari nabi.

Berdasarkan tradisi asalnya, tata cara maayun anak dalam upacara baayun maulid sebenarnya berasal tradisi bapalas bidan sebagai sebuah tradisi yang berlandaskan kepada kepercayaan Kaharingan. Dan ketika agama Hindu berkembang di daerah ini maka berkembang pula budaya yang serupa dengan baayun anak yakni baayun wayang (didahului oleh pertunjukan wayang), baayun topeng (didahului oleh pertunjukan topeng) dan baayun madihin (mengayun bayi sambil melagukan syair madihin). Ketika Islam masuk dan berkembang, upacara bapalas bidan tidak lantas hilang, meski dalam pelaksanaannya mendapat pengaruh unsur Islam. Islam datang tidak langsung menghilangkan tradisi Kaharingan dan Hindu sebelumnya tetapi tradisi yang dahulu itu disesuaikan dengan ajaran Islam dengan tujuan untuk mempermudah Islam masuk dan berkembang.

Keistemewaan dari ayunan yang digunakan ketika acara baayun maulid adalah tali ayunan dipenuhi hiasan dari janur (daun kelapa muda) berbentuk burung-burungan, ular-ularan, ketupat bangsur, halilipan, kambang sarai/hiasan dari kertas yang dipintal, hiasan dari wadai/kue 41 seperti cucur, cincin, pisang, nyiur dan lain-lain. Untuk tempat mengaitkan ayunan tersebut, panitia menyiapkan bambu yang panjang, di satu bambu ada terdapat sampai puluhan ayunan yang dikhususkan tempatnya untuk orang dewasa dan anakanak.

Adapun dengan ayunannya dibuat tiga lapis, dengan kain sarigading (sasirangan) pada lapisan pertama, kain kuning pada lapisan kedua dan kain bahalai (sarung panjang tanpa sambungan) pada lapisan ketiga. Orang tua yang melaksanakan baayun diharuskan menyiapkan piduduk (makanan) berupa beras, gula habang (gula merah), nyiur (kelapa), hintalu hayam (telur ayam kampung), banang (benang), jarum, uyah (garam) dan binggul (uang receh). Makanan ini menjadi lambang filosofis, seperti gula habang diharapkan anak yang diayun itu perkataan-perkataannya selalu memberikan kedamaian bagi orang yang disekitarnya. 
Pusat tempat dilaksanakan acara baayun maulid ini adalah di Masjid alKaramah desa Banua Halat Kabupaten Tapin. Peserta dalam acara ini tidak hanya dari anak-anak balita, tapi juga pemuda, orang dewasa, dan bahkan ada juga yang berusia sampai 100 tahun. Maksud mereka untuk mengikuti acara baayun maulid ini juga bermacam-macam. Ada yang mengaku untuk mencari berkah maulid agar anaknya pandai dan berbakti kepada orang tuanya dan ada juga yang melengkapi nazar mereka. Terlepas dari motif masing-masing peserta baayun yang nota-bene diikuti oleh orang-orang tua, maka maksud maayun anak bersamaan dengan peringatan maulid nabi adalah untuk membesarkan nabi sekaligus berharap berkah atas kemuliaan Nabi Muhammad Saw, disertai do'a agar sang anak yang diayun menjadi umat yang taat, bertaqwa kepada Allah Swt dan Rasul-Nya, serta kehidupannya sejak kecil maupun dewasa hatinya selalu terpaut untuk selalu shalat berjama'ah di mesjid. Total jumlah peserta yang mengikuti mencapai ribuan orang, terdiri dari golongan anak-anak (balita) dan orang dewasa bahkan ada berusia 60 tahunan. Bahkan tahun demi tahun peserta tersebut semakin bertambah bahkan ada dari negara tetangga seperti Malaysia dan Brunei.

Untuk di kota Banjarmasin-nya sendiri acara baayun maulid dilaksanakan di di komplek Makam Sultan Suriansyah, walaupun tidak sebesar yang ada di masjid al-Karamah desa Banua Halat Kabupaten Tapin. Walaupun ada yang tidak sepaham dengan komplek Makam Sultan Suriansyah tapi acara itu sudah ke tujuh kalinya dilaksanakan di sana.

\section{d. Batampung Tawar}

Batampung tawar adalah acara semacam selamatan untuk menyambut kelahiran seorang anak. Sama halnya dengan acara baayun maulid, ayunan yang digunakan juga digantungi macam-macam. Nantinya gantungan yang ada akan diperebutkan oleh orang-orang yang hadir.

Upacara Tepung Tawar sebagaimana dikenal masyarakat Indonesia dan Malaysia diadopsi dari ritual agama Hindu yang sudah lebih dulu dianut masyarakatnya. Ketika para pedagang dari Gujarat dan Hadralmaut membawa ajaran Islam ke kawasan ini sejak abad ke-7 Masehi, mereka berhadapan dengan kebiasaan animisme (kepercayaan pada kehidupan roh) dan dinamisme (kepercayaan pada kekuatan ghaib benda-benda) - yang direstui agama Hindu - yang sangat kuat di setiap lapisan masyarakat. Salah satunya adalah upacara Tepung Tawar (disebut juga Tepuk Tepung Tawar). Upacara ini menyertai berbagai peristiwa penting dalam masyarakat, seperti kelahiran, perkawinan, pindah rumah, pembukaan lahan baru, jemput semangat bagi orang yang baru luput dari mara bahaya, dan sebagainya. Dalam perkawinan, misalnya, Tepung Tawar adalah simbol pemberian do'a dan restu bagi kesejahteraan kedua pengantin, di samping sebagai penolakan terhadap bala dan gangguan.

Dalam upacara ini, penepung tawar menggunakan seikat dedaunan tertentu untuk memercikkan air terhadap orang yang ditepungtawari. Air 
tersebut terlebih dahulu diberikan wangi-wangian seperti jeruk purut, dicelupkan emas ke dalamnya, dan sebagainya. Selanjutnya, mereka menaburkan beras dan padi yang sudah dicampuri garam dan kunyit ke atas orang yang ditepungtawari. Akhirnya, mereka menyuapkan santapan pulut (atau lainnya) ke mulutnya. Ada anggapan bahwa setiap jenis daun dan bendabenda yang digunakan mempunyai atau merepresentasi kekuatan ghaib tertentu yang berfungsi menyelamatkan, menyejukkan, menjaga, dan sebagainya. Terdapat beberapa varian upacara ini untuk daerah yang berbeda (seperti Aceh, Melayu, Sambas dan lain-lain), tetapi sumber dan tujuannya sama.

Demikianlah yang dilakukan masyarakat sebelum Islam datang di nusantara dan demikian pulalah ritual yang sampai sekarang masih berlangsung dalam agama Hindu. Lihat saja baik secara langsung atau lewat televisi ritual orang-orang Hindu India atau Hindu Indonesia saat upacara keagamaan mereka.

Karena tidak mampu menghapuskan kebiasaan tersebut, para pembawa Islam yang terdahulu berusaha memasukkan nilai-nilai Islami ke dalamnya. Misalnya, acara Tepung Tawar diisi dengan pembacaan do'a kepada Allah Swt. Mereka menggiring masyarakat untuk menganggap bahwa Tepung Tawar itu hanya sebatas adat istiadat, penyebab setiap acara, bukan lagi ritual. Tetapi yang terjadi jauh panggang dari api. Upacara Tepung Tawar terus berlanjut dalam masyarakat yang takut untuk meninggalkannya. Berhubung para ulama kalah oleh tradisi (tidak berhasil menghilangkan kebiasaan tersebut), akhirnya masyarakat menganggap bahwa para ulama pun telah membenarkan mereka.

Sebagian kalangan bahkan beranggapan bahwa praktik Tepung Tawar memiliki sandaran agama. Beredar anggapan di tengah masyarakat bahwa praktik semacam ini dijalankan juga oleh para nabi dan keluarganya, termasuk isteri Nabi Imran a.s. yang menggunakan atau melemparkan suatu benda saat menazarkan kelahiran anaknya Maryam dan Nabi Muhammad SAW yang "menepungtawari" perkawinan Fatimah dengan Ali bin Abi Thalib.

Sebagian orang (termasuk oknum guru agama di kampung-kampung) mengatakan upacara Tepung Tawar adalah sunnat berdasarkan riwayat di atas. Tetapi sepengetahuan penulis, tidak ada ayat atau Hadits yang shahih tentang riwayat-riwayat semacam itu. Bahkan, cerita-cerita tersebut kalau kurang hatihati cenderung kepada dosa besar karena mendustakan para nabi yang mulia. Rasulullah SAW bersabda dalam sebuah Hadits shahih bahwa barangsiapa sengaja meriwayatkan darinya sesuatu yang tidak pernah beliau lakukan atau katakan maka orang itu tempatnya di dalam neraka.

\section{e. Bapalas bidan}

Kelahiran dan kematian adalah siklus kehidupan manusia. Dalam masyarakat Banjar dalam kelahiran seorang anak akan dimulai dengan beberapa tradisi salah satunya bapalas bidan. Segera setelah lahir, tangkai pusat bayi langsung dipotong dan kemudian dibungkus dengan kunyit 
bercampur kapur, bayi dimandikan, diwudhui, perutnya diolesi dengan bedak beras (Alfani Daud, 1997; 230), ubun-ubunnya dikasai (diolesi) dengan ramuan beras dan garam lalu seluruh tubuhnya dibalut dengan kain bersih termasuk kedua tanggannya (dibedong). Tembuni bayi dibersihkan dan dicampurkan dengan garam, ada kepercayaan masyarakat Banjar apabila tembuni seorang bayi dicampur dengan garam, maka perkataan-perkataan bayi kelak akan masin (berpengaruh/penuh dengan hikmah) (Alfani Daud, 1997; 232).

Masyarakat Banjar terkenal dengan agamis, terbukti ketika bayi baru lahir diazankan di telinga sebelah kanan dan diiqamatkan di telinga sebelah kiri. Masyarakat Banjar biasanya menambahkan surah al-Inshirah dan surah alQadr kemudian ditiupkan dengan pelan ke telinga bayi. Hal demikian pun mereka lakukan ketika sedang memandikan bayi sampai bayi berumur 40 hari. Apabila azan maghrib berkumandang bayi yang sedang berbaring segera diangkat dan diayun-ayun seraya membacakan surah al-Qadr sebanyak 3 kali dan kemudian ditiupkan ke telinga bayi dengan niatan bayi tidak diganggu makhluk ghaib.

Masyarakat Banjar juga masih percaya dengan hal yang berbau mistis seperti terlebih bayi masih berumur di bawah 40 hari maka diletakkan di samping/dekat kepala bayi cermin, surah Yasin, bawang tunggal, daun jariangau (jeringau) dan jeruk nipis. Hal itu dimaksudkan agar bayi tersebut tidak diganggu kuyang dan hantu beranak serta saudara-saudara ghaibnya yang lain.

Menurut Daud seorang bayi yang baru lahir dinyatakan sebagai anak bidan sampai dilaksanakannya upacara bapalas bidan, yakni suatu upacara pemberkatan yang dilakukan oleh bidan terhadap si bayi dan ibunya. Selain dilaksanakan oleh masyarakat Banjar yang tinggal di pedesaan, upacara bapalas bidan juga dilaksanakan oleh orang Dayak Meratus. Setelah bayi lahir, orang Dayak Meratus kemudian melaksanakan upacara bapalas bidan, yakni memberi hadiah (piduduk) berupa lamang ketan, sumur-sumuran (aing terak), beras, gula dan sedikit uang kepada bidan atau balian yang menolong. Biasanya sekaligus pemberian nama kepada sang bayi. Termasuk nantinya saat anak sudah mulai berjalan (turun) ke tanah dari rumah (umbun) juga dengan upacara mainjak tanah, tetap dipimpin oleh balian. Pelaksanaan bapalas bidan, biasanya dilakukan ketika bayi berumur 40 hari.

Bapalas bidan selain dimaksudkan sebagai balas jasa terhadap bidan, juga merupakan penebus atas darah yang telah tumpah ketika melahirkan. Dengan pelaksanaan bapalas bidan ini diharapkan tidak terjadi pertumpahan darah yang diakibatkan oleh kecelakaan atau perkelahian di lingkungan tetangga maupun atas keluarga sendiri. Karena menurut kepercayaan darah yang tumpah telah ditebus oleh si anak pada upacara bapalas bidan tersebut. Pada upacara bapalas bidan ini si anak dibuatkan buaian (ayunan) yang diberi hiasan yang menarik, seperti udang-udangan, belalang dan urung ketupat berbagai bentuk, serta digantungkan bermacam kue seperti cucur, cincin, 
apam, pisang dan lain-lain. Kepada bidan yang telah berjasa menolong persalinan itu diberikan hadiah segantang beras, jarum, benang, seekor ayam (jika bayi lahir laki-laki, maka diserahkan ayam jantan dan jika perempuan diberikan ayam betina), sebiji kelapa, rempah-rempah dan bahan untuk menginang seperti sirih, kapur, pinang, gambir, tembakau dan berupa uang. Karena memang berasal dari tradisi pra-Islam, maka di antara perlengkapan baayun maulid seperti ayunan dan piduduk mempunyai persamaan dengan perlengkapan langgatan pada acara tradisional aruh ganal yang dilaksanakan orang Dayak Meratus.

Ketika Islam datang ke daerah ini, acara bapalas bidan dan maayun anak tidak dilarang, hanya kebiasaan yang tidak sesuai sedikit demi sedikit ditinggalkan. Begitu pula berbagai perlengkapan, maksud dan tujuan, dan perlambang (simbolika) juga disesuaikan atau diisi dengan nilai-nilai Islam. Perbedaan yang ada antara ritual Hindu dan Islam ketika melakukan ritual adalah dalam Hindu selalu menggunakan mantra-mantra sedangkan dalam Islam selalu disisipkan bacaan al-Quran dan shalawat kepada nabi Muhammad.

\section{f. Baarwahan dan Bahaulan}

Di kalangan masyarakat Banjar, peristiwa kematian umumnya tidak selesai dengan dikuburkannya mayat. Ia diiringi dengan berbagai acara selamatan atau aruh. Yaitu pada hari pertama (manurun tanah), hari ketiga (manigahari), ketujuh (mamitunghari), kedua puluh lima (manyalawi), ke empat puluh (maampatpuluh hari), ke seratus (manyaratus), sesudah setahun dan setiap tahunnya.

Dalam acara tersebut selalu ada bacaan al-Quran, shalawat kepada Nabi serta tahlil yang hadiahnya ditujukan kepada mayat yang bersangkutan. Dan diakhiri dengan bacaan do'a haul atau arwah. Do'a arwah berisi permohonan kepada Allah agar apa yang dibaca berupa bacaan Al-Qur'an, shalawat kepada Nabi serta tahlil diberikan pahala yang besar, dan menghadiahkan pahala tersebut kepada Nabi Muhammad, kepada orang-orang suci (wali), kepada roh orang tua, seluruh kaum muslimin dan muslimat serta mukminin dan mukminat khususnya kepada ruh (biasanya disebutkan namanya dengan jelas atau juga dalam hati di pembaca do'a).

Undangan yang menghadiri acara ini biasanya (dihari pertama sampai hari keseratus) merupakan kerabat dari si mayat. Adapun acara haul undangan yang menghadiri lebih diperluas lagi tidak sekedar dari pihak keluarga si mayat tapi orang kampung sebelah mereka pun ikut diundang juga.

\section{Penutup}

Di Kalimantan Selatan, yang biasa disebut sebagai orang Banjar adalah penduduk (asli) daerah sekitar kota Banjarmasin (wilayah Sungai Jingah, Kuin 
dan Kampung Melayu). Daerah ini meluas sampai kota Martapura, ibukota kabupaten Banjar dan wilayah sekitarnya.

Bahasa yang digunakan oleh masyarakat Banjar adalah bahasa Banjar. Bahasa Banjar sejatinya adalah pecahan dari bahasa Melayu. Karena diduga kuat bahwasanya nenek moyang masyarakat Banjar adalah berintikan pecahan suku bangsa Melayu yang dikembangkan oleh suku bangsa yang mendiami Sumatera dan Tanah Semenanjung Melayu (sekarang Malaysia Barat) sekitar lebih dari seribu tahun yang lalu berimigrasi secara besar-besaran ke kawasan Kalimantan khususnya Kalimantan Selatan.

Sebelum Islam masuk ke pulau Kalimantan, penduduknya telah memeluk agama Hindu-Budha atau memeluk kepercayaan Kaharingan yang tentu saja sangat berbeda dengan ajaran Islam. Walaupun proses Islamisasi masyarakat Kalimantan hingga kini terus berjalan melalui dakwah dan pendidikan, akan tetapi bekas-bekas kepercayaan dan budaya agama sebelumnya, tidak sepenuhnya bisa dikikis sehingga sebagian masih berpengaruh terhadap keberagamaan dan kebudayaan umat Islam hingga sekarang ini.

Islam dan budaya Banjar merupakan dua hal yang tidak dapat dipisahkan dalam kehidupan bermasyarakat beragama mereka seperti Hari alSyura (10 Muharram) dan bubur al-Syura, maulidan, baayun maulid, batampung tawar, bapalas bidan, baarwahan dan bahaulan. Tradisi di atas yang semakin jarang ditemui adalah bapalas bidan. Sebaiknya tradisi ini diperkenalkan kembali kepada masyarakat Kalimantan Selatan khususnya masyarakat suku Banjar baik itu dilakukan oleh pemerintah maupun tokoh masyarakat sehingga tradisi terjaga. 


\section{DAFTAR PUSTAKA}

Buseri, Kamrani, Sepintas Masuknya Islam Di Borneo, artikel, 28 Desember 2009

Daud, Alfani, Islam dan Masyarakat Banjar: Diskripsi dan Analisa Kebudayaan Banjar Jakarta: RajaGrafindo Persada, 1997.

Geertz, Clifford, Abangan, Santri, Priyayi dalam Masyarakat Jawa diterjemahkan Aswan Mahasin, Jakarta: Dunia Pustaka Jaya, 1983.

http://bubuhanbanjar.wordpress.com/2011/02/14/menyoal-baayun-maulid-dikomplek-makam-sultan-suriansyah/.

http://ruslihasbi.wordpress.com/tanya-jawab/akidah/ch/

http://wahanacerita-miranda.blogspot.com/2010/04/bingkai-budaya-dalamkebersamaan.html

http://www.kalselprov.go.id/berita-daerah/puluhan-ribu-umat-hadiri-baayunmaulid.

Munadi, Fathullah, Syekh Arsyad Al-Banjari; dalam Konteks Kajian Al-Quran di Nusantara, Banjarmasin: Antasari Press, 2011.

Sani, Mukhyar, Jurnal Al-Hadarah, Vol. 2 No 3, Januari-Juni 2003 dalam Dakwah Islam dan Perkembangannya di Kalimantan Selatan.

Zaehner, R.C, Mistisisme Hindu Muslim, diterjemahkan Suhadi, Yogyakarta: LKiS, 2004.

Zuhri, Saifuddin Sejarah Kebangkitan Islam dan Perkembangannya di Indonesia, Bandung: PT Al-Ma'arif, 1980. 